\title{
GENOTOXICITY OF N-HYDROXY AND AMINOPHENOL METABOLITES OF 2,6- AND 3,5-DIMETHYLANILINE AT THE HYPOXANTHINEGUANINE PHOSPHORIBOSYLTRANSFERASE LOCUS IN TK6 CELLS
}

\author{
SEO HYUN MOON ${ }^{1}$, MIN YOUNG KIM ${ }^{2 *}$ \\ ${ }^{1}$ Department of Forensic DNA, National Forensic Service, Wonju, Gangwon-do, Republic of Korea. ${ }^{2}$ Toxicology Laboratory, Faculty of \\ Biotechnology (Biomaterials), College of Applied Life Science, SARI, Jeju National University, Jeju, Republic of Korea. \\ Email: jeffmkim@jejunu.ac.kr
}

Received: 08 June 2018, Revised and Accepted: 09 July 2018

\section{ABSTRACT}

Objective: The objective of this study as to characterize the genotoxicity of reactive metabolites of 2,6-dimethylaniline (2,6-DMA) and 3,5-DMA in the hypoxanthineguanine phosphoribosyltransferase (HPRT) gene of human lymphoblastoid TK6 cells.

Methods: Cultures were exposed to $N$-hydroxylamine and aminophenol metabolites of 2,6- and 3,5-DMA for $1 \mathrm{~h}$ in serum-free medium. Cell survival $24 \mathrm{~h}$ after exposure was determined by trypan blue exclusion. Cells were then subcultured for 7-10 days to allow to phenotypic expression of HPRT mutants. After the expression period, cells were plated in the presence of $2 \mu \mathrm{g} / \mathrm{ml} 6$-thioguanine for the selection of $H P R T$ mutants. Plating efficiency was determined and mutant fraction calculated. Electron paramagnetic resonance (EPR) was also used to determine whether 3,5- dimethylaminophenol (DMAP) produced reactive oxygen species (ROS).

Results: All of the metabolites tested were cytotoxic to these cells but exhibited a considerable variation in potency. The aminophenol metabolites of 2,6- and 3,5-DMA were considerably more toxic than the corresponding $N$-hydroxylamines. Furthermore, each metabolite of 3,5-DMA was more toxic than its 2,6-DMA counterpart; $N$-OH-3,5-DMA and 3,5-DMAP were clearly mutagenic at a level of $50 \mu \mathrm{M}$. EPR studies showed intracellular oxidative stress induced under 3,5-DMAP treatment.

Conclusions: Our findings suggest that genotoxic responses of 2,6- and 3,5-DMA are mediated through the generation of ROS by hydroxylamine and/ or aminophenol metabolites.

Keywords: Dimethylaniline, Metabolites, Genotoxicity, TK6/HPRT assay, ROS

(C) 2018 The Authors. Published by Innovare Academic Sciences Pvt Ltd. This is an open access article under the CC BY license (http://creativecommons. org/licenses/by/4. 0/) DOI: http://dx.doi.org/10.22159/ajpcr.2018.v11i9.27820

\section{INTRODUCTION}

Alkylanilines are abundantly found environmental chemicals, mainly tobacco smoke and hair dyes. They are considered factors for the development of bladder cancer [1]. Most common alkylanilines in the environment are 2,6-dimethylaniline (2,6-DMA) and 3,5-dimethylaniline ((3,5-DMA). They are metabolized by CYP450s to N-hydroxy-DMA through N-hydroxylation or dimethylaminophenol (DMAP), which can further be metabolized to dimethylquinone imine and then go through redox cycling to generate reactive oxygen species (ROS) [1,2].

Although 2,6-DMA has been shown to be clearly mutagenic for Salmonella typhimurium and a rodent nasal cavity carcinogen [3], categorized by IARC as possibly carcinogenic to humans (Group 2B), and it has been shown to form DNA adducts in rats [4], evidence linking exposure to 3,5-DMA, which are structurally closed related to 2,6-DMA, to genotoxicity or carcinogenicity is less extensive. Recently, the mutagenic potential of 3,5-DMA was assessed in the gpt gene of AS52 cells and aprt gene of AA8 cells [2,5,6]. 3,5-DMA was mutagenic and cytotoxic in AS52 cells when activated by P450-mediated hydroxylation and phase II conjugation, in which the aminophenol metabolites were considerably more potent than the corresponding $\mathrm{N}$-hydroxylamines [2,5], whereas 3,5-DMAP did not caused a statistically significant increase in mutation frequency in AA8 cells [5,6]. In the absence of animal models, in vitro studies become particularly important in providing information on the carcinogenic mechanisms of 3,5-DMA. Therefore, all agree that other assays require further study for the understanding of mutagenesis caused by 3,5 -DMA and its metabolites. The most promising mutation assays seem to be the hypoxanthine phosphoribosyltransferase (HPRT) assay. The HPRT gene is on the X chromosome of mammalian cells, and it is used as a model gene to investigate gene mutations in mammalian cell lines [7]. The assay can detect a wide range of chemicals capable of causing DNA damage that leads to gene mutation [7].

In the present study, we have begun testing the hypothesis that their genotoxic effects are mediated through N-hydroxylamine and/or aminophenol metabolites. Target cells used for these experiments include human lymphoblastoid TK6 cells, which have been used extensively in mutagenicity studies. We also used electron paramagnetic resonance (EPR) to test ROS production by aminophenol metabolites of DMA.

\section{METHOD}

\section{Chemicals and reagents}

Reagents and cell culture materials were purchased from the following sources: Cell culture materials, Lonza (Walkersville, MD); fetal bovine serum, Atlanta Biological; 2,6-DMA, 6-thioguanine (6-TG), 5,5-dimethyl1 -pyrroline $N$-oxide (DMPO), and dimethyl sulfoxide (DMSO), Sigma Chemical Co., St Louis, MO; superoxide dismutase (SOD, $5000 \mathrm{U} \mathrm{mg}$ ) and beef liver catalase (CAT, $65000 \mathrm{U} / \mathrm{mg}$ ), Roche Diagnostics (Indianapolis, IN, US); and 3,5-DMA, Acros Organics (Geel, Belgium).

\section{Cell cultures}

TK6 cells, provided by Dr. Wogan (Massachusetts Institute of Technology), were maintained in RPMI 1640 medium supplemented with antibiotics and $10 \%$ heat-inactivated horse serum (Lonza, 
Walkersville, MD). Before each experiment, they were treated with CHAT $(10 \mu \mathrm{M} 2$ 2'-deoxycytidine, $20 \mu \mathrm{M}$ hypoxanthine, $0.1 \mu \mathrm{M}$ aminopterin, and $17.5 \mu \mathrm{M}$ thymidine) according to a standard protocol to remove preexistent mutant cells

Treatments with $\mathrm{N}$-hydroxy and aminophenol metabolites of 2,6- and 3,5-DMA

N-hydroxy and aminophenol metabolites of 2,6- and 3,5-DMA were synthesized as described previously [5]. The cells were seeded at $1 \times 10^{6}$ and incubated overnight with the regular medium. Then, medium changed to one without serum and cells were treated in triplicate with $0-250 \mu \mathrm{M}$ of $\mathrm{N}$-hydroxy or aminophenol metabolites for $1,2,4$, and $24 \mathrm{~h}$. After treatment, the culture was washed with PBS, amended with RPMI 1640 medium containing 10\% horse serum, and incubated.

\section{Measurement of survival and HPRT mutations}

Cytotoxicity was determined by trypan blue exclusion assay $24 \mathrm{~h}$ after treatment. Specifically, conditions were chosen which resulted in 35$50 \%$ survival $1 \mathrm{~h}$ after exposure because previous studies shown that such conditions optimize statistical estimation of MF $[8,9]$. TK6 cells were maintained for 7 days to allow phenotypic expression, at which time a total of $24 \times 10^{6}$ cells were placed into ten 96 -well microtiter plates at densities of $4 \times 10^{4}$ cells/well in medium containing $2 \mu \mathrm{g} / \mathrm{mL}$ of 6 -TG to select HPRT mutants, respectively. For plating efficiency, cells from each culture were also plated into 96 -well dishes at 1 cell $/ 100 \mu \mathrm{L} /$ well in the absence of selective agents. After 2 weeks of incubation, colonies were counted and mutation fractions (MFs) were calculated as described by Kim [10]. Identified single HPRT mutant colony was then transferred to 24 -well plates for propagating mutant cells. Approximately $2 \times 10^{6}$ mutant cells were collected for molecular analysis. The spontaneous MF was estimated from the argon-treated cells for NO* treatment or untreated cells for coculture. Cells treated with 4-NQO (140 ng/mL for $1.5 \mathrm{~h}$ ) served as positive controls.

\section{EPR spectroscopy}

TK6 cells $\left(1 \times 10^{7}\right)$ were gently washed twice with RPMI-serum-free media and then resuspended $400 \mu \mathrm{L}$ of serum-free media. An aliquot of $400 \mu \mathrm{L}$ was mixed with DMPO (100 mM), 3,5-DMAP (2 mM), and NADPH (15 mM) and placed into flat cell. Measurements were carried out using $0.3-\mathrm{mm}$ flat cell. All reaction mixtures were air-saturated for the EPR experiments. EPR experiment run by a Broker EMX-300 spectrometer (Bruker, Billerica, MA) operating at modulation frequency $100 \mathrm{kHz}$; microwave frequency, 9.17 GHz; modulation amplitude, $0.5 \mathrm{G}$; and receiver gain, $1 \times 10^{4}$.

\section{Statistical analysis}

All experiments were repeated 2-4 times. The two-tailed Student's $t$-test (SPSS for Windows, 12.0, SPSS Inc. Chicago, IL, USA) was used for the comparison of test and control groups, and $\mathrm{p}<0.05$ and 0.01 were considered to be statistically significant.

\section{RESULTS AND DISCUSSION}

Time-course analysis of cell survival

To determine the suppression of cell growth by N-hydroxy and aminophenol metabolites of 2,6- and 3,5-DMA in human lymphoblastoid cells, TK6 cells were treated with various doses of N-hydroxy and aminophenol metabolites of 2,6- and 3,5-DMA for 1, 2, 4, or $24 \mathrm{~h}$. As shown in Table $1, \mathrm{~N}$-hydroxy and aminophenol metabolites of 2,6- and 3,5-DMA exerted cell growth inhibitory effects on TK6 cells in a dose- and time-dependent manner. The growth of the TK6 cells was markedly suppressed following $24 \mathrm{~h}$ treatment with the highest concentrations of each metabolite, N-hydroxy-2,6- and 3,5-DMA (250 and $100 \mu \mathrm{M}$ ), and 2,6- and 3,5-DMAP (25 and $25 \mu \mathrm{M}$ ) an 97.1-99.3\% reduction as compared with the untreated control cells $(\mathrm{p}<0.01)$ (Table 1). Aminophenols were far more toxic at low concentration than $\mathrm{N}$-hydroxylamines, and N-hydroxy and aminophenol metabolites of 3.5DMA were more toxic than those of 2-6-DMA. Cell viability was $0.7 \%$ in TK6 cells $24 \mathrm{~h}$ after treatment with $25 \mu \mathrm{M}$ of 3,5-DMAP (Table 1).

Cytotoxicity and mutagenicity of $\mathrm{N}$-hydroxy and aminophenol metabolites of 2,6- and 3,5-DMA to TK6 cells

The alkylanilines proposed for the study are closely related structurally and would all likely be metabolized to N-hydroylamines in vivo [11]. A fraction of the alkylanilines may also be metabolically transformed to DNA reactive quinone imines [12]. Direct genotoxicity as a by-product of $\mathrm{N}$-hydroxylamine or quinone imine formation is the expected carcinogenic mode of action for the chemicals [11,12]. In the present experiments, when TK6 cells were exposed for $1 \mathrm{~h}$ to N-hydroxy-2,6 and 3,5-DMA, cell death was induced in a dose-dependent manner (Fig. 1a). N-hydroxy-3,5-DMA was more toxic than N-hydroxy-2,6DMA; cell viability was $44 \%$ in TK6 cells $1 \mathrm{~h}$ after a dose of $25 \mu \mathrm{M}$ of $\mathrm{N}$-hydroxy-3,5-DMA, as compared to $35 \%$ after treatment with $100 \mu \mathrm{M}$ of N-hydroxy-2,6-DMA, respectively (arrows in Fig. 1a). Mutagenicity of N-hydroxy-2,6- and 3,5-DMA in the HPRT gene of TK6 cells was also investigated (Fig. 1b). At a dose of $100 \mu \mathrm{M}$ in N-hydroxy-2,6DMA and $25 \mu \mathrm{M}$ in N-hydroxy-3,5-DMA-treated TK6 cells, induced mutation frequencies in the HRPT gene were $1.31 \times 10^{-5}(\mathrm{p}<0.05)$ and $1.73 \times 10^{-5}(\mathrm{p}<0.05), 3$ - and 4-fold higher than background $\left(0.43 \times 10^{-5}\right)$, respectively (Fig. 1b).

A dose-dependent decrease in the viability of TK6 cells after treatment with 2,6- and 3,5-DMAP is shown in Fig. 2a. Aminophenol metabolites were more cytotoxic than N-hydroxy metabolites; cell viability in 3,5- and 2,6-DMAP was 39 and 53\% after a dose of 10 and $40 \mu \mathrm{M}$ for

Table 1: Cell survival after treatment with $N$-OH-2,6-DMA, $N$-OH-3,5-DMA, 2,6-DMA, P and 3,5-DMAP in TK6 cells

\begin{tabular}{|c|c|c|c|c|c|}
\hline & \multirow[t]{2}{*}{ Dose $(\mu \mathrm{M})$} & \multicolumn{4}{|l|}{ Survival (\%) } \\
\hline & & $1 \mathrm{~h}$ & $2 \mathrm{~h}$ & $4 \mathrm{~h}$ & $24 \mathrm{~h}$ \\
\hline \multirow[t]{3}{*}{ N-OH-2,6-DMA } & 0 & 100 & 100 & 100 & 100 \\
\hline & 100 & $35.4 \pm 1.21^{* *}$ & $28.1 \pm 1.02^{* *}$ & $19.4 \pm 1.29 * *$ & $14.7 \pm 2.12^{* *}$ \\
\hline & 250 & $19.9 \pm 1.04^{* *}$ & $3.6 \pm 0.92 * *$ & $5.7 \pm 0.44^{* *}$ & $1.4 \pm 0.32^{* *}$ \\
\hline \multirow[t]{4}{*}{ N-OH-3,5-DMA } & 0 & 100 & 100 & 100 & 100 \\
\hline & 10 & $72.5 \pm 3.22 *$ & $69.3 \pm 3.41^{* *}$ & $66.8 \pm 4.12^{* *}$ & $62.3 \pm 2.35^{* *}$ \\
\hline & 50 & $34.6 \pm 2.81^{* *}$ & $21.3 \pm 2.04^{* *}$ & $20.0 \pm 1.84^{* *}$ & $17.9 \pm 0.89 * *$ \\
\hline & 100 & $15.7 \pm 0.04^{* *}$ & $7.9 \pm 0.23^{* *}$ & $5.2 \pm 1.15^{* *}$ & $2.9 \pm 0.51^{* *}$ \\
\hline \multirow[t]{4}{*}{ 2,6-DMAP } & 0 & 100 & 100 & 100 & 100 \\
\hline & 5 & $82.8 \pm 3.21^{*}$ & $50.5 \pm 2.14^{* *}$ & $45.2 \pm 2.87^{* *}$ & $62.3 \pm 4.11^{* *}$ \\
\hline & 10 & $60.1 \pm 3.46^{* *}$ & $40.6 \pm 1.89 * *$ & $33.0 \pm 1.25^{* *}$ & $17.9 \pm 0.86^{* *}$ \\
\hline & 25 & $42.9 \pm 2.56^{* *}$ & $34.6 \pm 3.51^{* *}$ & $19.9 \pm 2.88^{* *}$ & $2.9 \pm 0.41^{* *}$ \\
\hline \multirow[t]{3}{*}{ 3,5-DMAP } & 0 & 100 & 100 & 100 & 100 \\
\hline & 5 & $55.7 \pm 2.14^{* *}$ & $53.5 \pm 3.14^{* *}$ & $38.3 \pm 2.21^{* *}$ & $36.3 \pm 2.10^{* *}$ \\
\hline & 10 & $35.7 \pm 3.12^{* *}$ & $29.5 \pm 1.12^{* *}$ & $14.1 \pm 1.37^{* *}$ & $19.1 \pm 0.98^{* *}$ \\
\hline
\end{tabular}

Each values is expressed as mean \pm standard deviation $(\mathrm{n}=3),{ }^{*} \mathrm{p}<0.05$ and ${ }^{* *} \mathrm{p}<0.01$ compared to vehicle control, DMAP: Dimethylaminophenol 
$1 \mathrm{~h}$ (arrows in Fig. 2a), as compared to $44 \%$ and 35\% after treatment with $25 \mu \mathrm{M}$ of N-hydroxy-3,5-DMA and $100 \mu \mathrm{M}$ of N-hydroxy-2,6-DMA, respectively (Fig. 1a). The MFs induced by exposure to $10 \mu \mathrm{M}$ in 3,5DMAP and $40 \mu \mathrm{M}$ in 2,6-DMAP for $1 \mathrm{~h}, 9.6$ and $7.6 \times 10^{-5}(\mathrm{p}<0.01)$, were 13 - and 11 -fold higher than the background MF, $0.69 \times 10^{-5}$, respectively (Fig. 2b). By comparison, in 4-NQO-treated positive controls, MF at the HPRT locus was 1.24 and $1.4 \times 10^{-5}$ (Figs. $1 \mathrm{~b}$ and $2 \mathrm{~b}$ ).

\section{ROS production by 3,5-DMAP}

A growing body of evidence points toward oxygen-free radicals being involved in carcinogenesis and a wide variety of degenerative diseases [13-15]. Oxidative damage may become a threat under conditions of oxidative stress, where defense and repair mechanisms are defective or are overwhelmed by the excessive generation of ROS [16]. Previous studies shown that the mechanism, by which the alkylanilines 2,6-DMA and 3,5-DMA would generate ROS in vivo, involves initial oxidative metabolism to an aminophenol, which then can cycle through the corresponding quinone imine structure [5]. In the present study, the possible protective effects of SOD and CAT against the ROS-producing and cytotoxic effects of 3,5-DMAP were investigated by measuring intracellular ROS production and cell viability. As shown in Fig. 3, TK6 cells were exposed to 3,5-DMAP $(5,10$, and $25 \mu \mathrm{M})$ for $24 \mathrm{~h}$, and intracellular ROS production and cell survival were measured. Cell viability after treatment with 3,5-DMAP decreased by $42 \%$ at $5 \mu \mathrm{M}$, whereas inhibition of ROS with $500 \mathrm{U}$ SOD and $500 \mathrm{U}$ CAT restored the cell survival to a rate near that of control (81\%). The chemical character of the ROS production from the samples treated with $2 \mathrm{mM}$ of 3,5-DMAP as well as its changes caused by cotreatment with SOD and CAT was estimated based on the simulation of EPR spectra. The EPR peak height increased with increases in 3,5-DMAP (Fig. 3b). The addition of $500 \mathrm{U}$ of SOD and CAT resulted in markedly decreases in EPR peak height, suggesting that removal of ROS generated from 3,5-DMAP (Fig. 3b). These data are consistent with the recent demonstration that both hydroxylamine and aminophenol metabolites of both 2,6- and 3,5-DMA were capable of producing ROS intracellularly and that the aminophenols were far more potent [5] and antioxidant enzymes such as $\mathrm{N}$-acetyl cysteine, ascorbate, SOD, CAT, uric acid, and tiron rescue the incidence of 3,5-DMAP-induced mutagenesis in cultured mammalian cells $[5,14]$.

\section{CONCLUSION}

The N-hydroxy and aminophenol metabolites of 2,6- and 3,5-DMA can cause both cytotoxicity and mutagenicity in the HPRT gene of TK6 cells. Our result also implicates ROS as mediators of 2,6- and 3,5DMA genotoxicity. Further research will be required to define more specifically the mechanisms through which they act.

\section{ACKNOWLEDGMENT}

This work was supported by Basic Science Research Program (2017R1D1A1B03028849, 2016R1A6A1A03012862, and 2014R1A1A2056292) through the National Research Foundation of Korea (NRF) funded by the Ministry of Education, Science, and Technology, Republic of Korea.

\section{AUTHORS' CONTRIBUTION}

All authors had equally contributed to the research work.

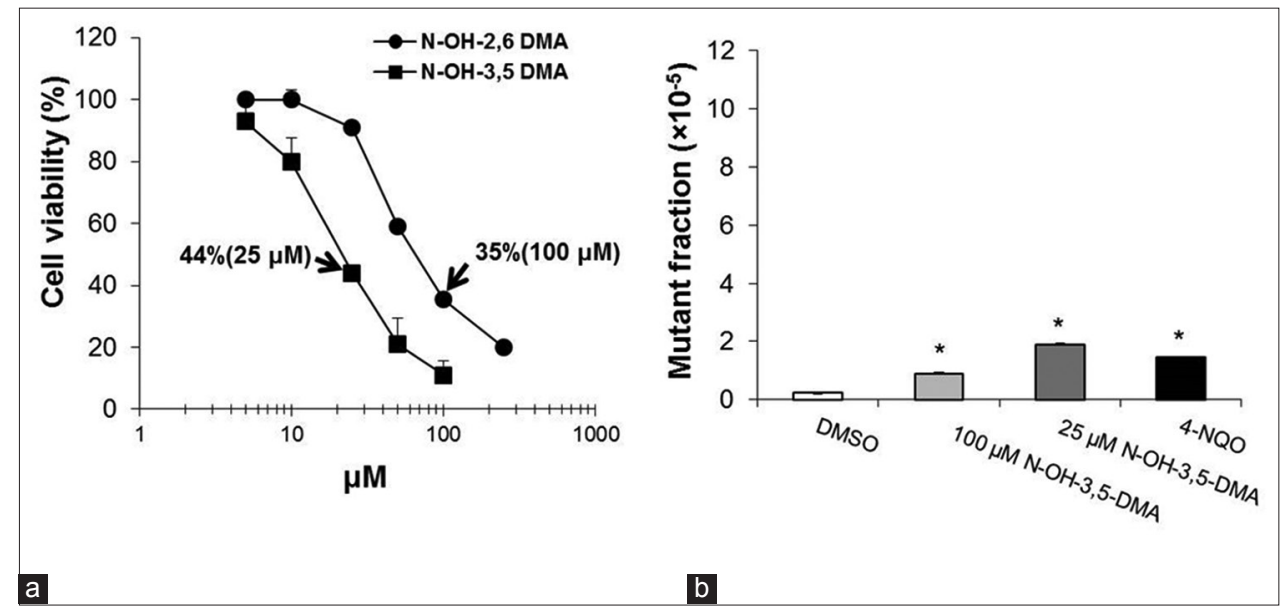

Fig. 1: Cell survival (a) and induced mutation fraction (b) in AS52 cells treated with N-hydroxy metabolites of 2,6-DMA and 3,5-DMA for 1 $h$, results ( $a$ and $b)$ are shown as the mean standard deviation $(n=3),{ }^{*} \mathbf{p}<0.05$ and ${ }^{* *} \mathbf{p}<0.01$ compared to vehicle (DMSO) control

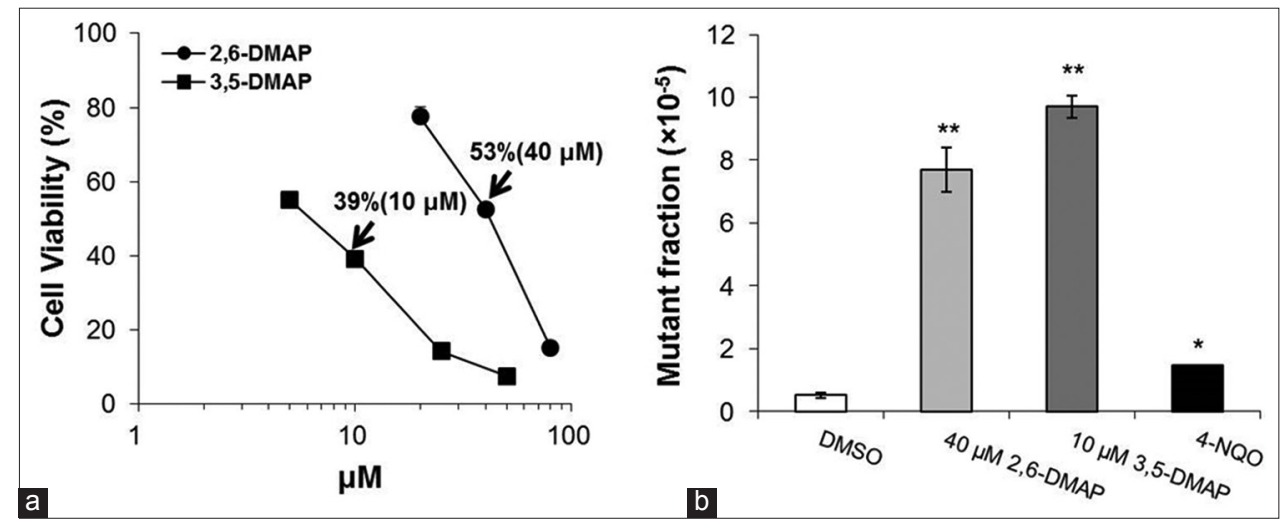

Fig. 2: Cell survival (a) and induced mutation fraction (b) in AS52 cells treated with aminophenol metabolites of 2,6-DMA and 3,5-DMA for $1 \mathrm{~h}$, results ( $\mathrm{a}$ and $\mathrm{b}$ ) are shown as the mean \pm standard deviation, ${ }^{*} \mathrm{p}<0.05$ and ${ }^{* *} \mathrm{p}<0.01$ compared to vehicle (DMSO) control 


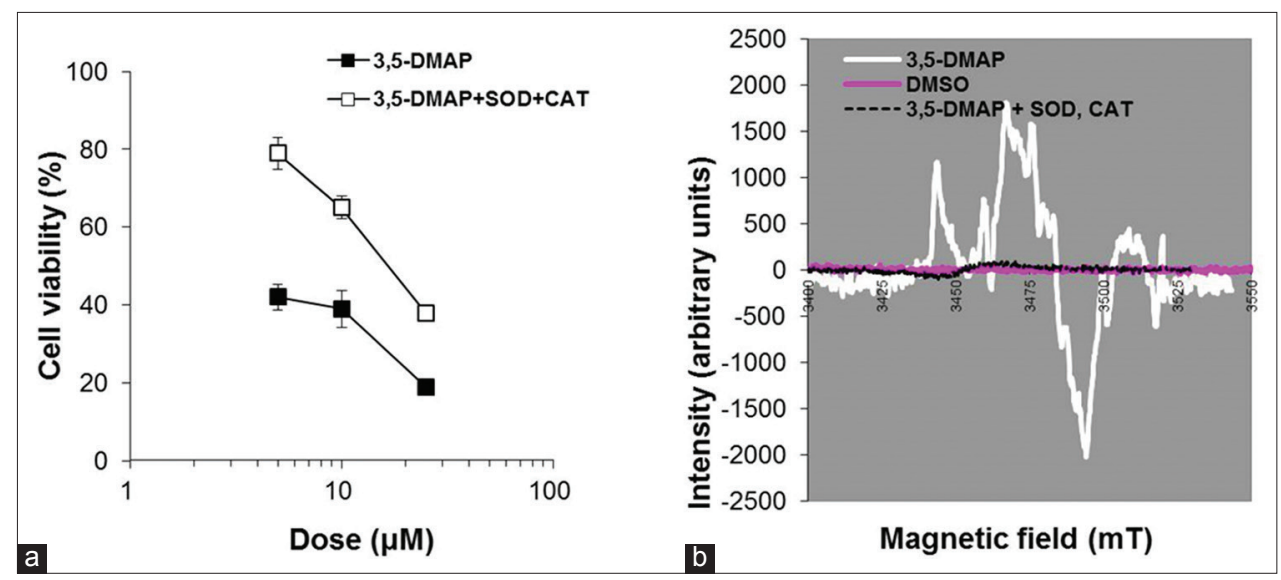

Fig. 3: Survival of TK6 cells (a) and electron paramagnetic resonance spectra (b) after treatment with 3,5-dimethylaminophenol for $24 \mathrm{~h}$ in the absence or presence of superoxide dismutase and catalase, results ( $a$ and $b$ ) are shown as the mean standard deviation ( $n=3$ )

\section{CONFLICTS OF INTEREST}

We declare that there are no conflicts of interest.

\section{REFERENCES}

1. Skipper PL, Kim MY, Sun HL, Wogan GN, Tannenbaum SR. Monocyclic aromatic amines as potential human carcinogens: Old is new again. Carcinogenesis 2010;31:50-8.

2. Moon SH, Kim MY. Mutational specificity of 2, 6-dimethylaniline with in vitro human S9 metabolic activation in the GPT gene of AS52 cells. Int J Pharm Pharm Sci 2018;10: In press.

3. National Toxicology Program. NTP toxicology and carcinogenesis studies of 2,6-xylidine (2,6-dimethylaniline) (CAS no 87-62-7) in Charles river CD rats (Feed studies). Natl Toxicol Program Tech Rep Ser 1990;278:1-38.

4. Short CR, Joseph M, Hardy ML. Covalent binding of [14C]-2,6dimethylaniline to DNA of rat liver and ethmoid turbinate. J Toxicol Environ Health 1989;27:85-94

5. Chao MW, Kim MY, Ye W, Ge J, Trudel LJ, Belanger CL, et al. Genotoxicity of 2,6- and 3,5-dimethylaniline in cultured mammalian cells: The role of reactive oxygen species. Toxicol Sci 2012;130:48-59.

6. Chao MW, Erkekoglu P, Tseng CY, Ye W, Trudel LJ, Skipper PL, et al. Protective effects of ascorbic acid against the genetic and epigenetic alterations induced by 3,5-dimethylaminophenol in AA8 cells. J Appl Toxicol 2015;35:466-77.

7. Burkhart-Schultz KJ, Thompson CL, Jones IM. Spectrum of somatic mutation at the hypoxanthine phosphoribosyltransferase (hprt) gene of healthy people. Carcinogenesis 1996;17:1871-83.

8. Li CQ, Trudel LJ, Wogan GN. Nitric oxide-induced genotoxicity, mitochondrial damage, and apoptosis in human lymphoblastoid cells expressing wild-type and mutant p53. Proc Natl Acad Sci U S A 2002;99:10364-9.

9. Li CQ, Trudel LJ, Wogan GN. Genotoxicity, mitochondrial damage, and apoptosis in human lymphoblastoid cells exposed to peroxynitrite generated from SIN-1. Chem Res Toxicol 2002;15:527-35.

10. Kim MY. Intracellular and extracellular factors influencing the genotoxicity of nitric oxide and reactive oxygen species. Oncol Lett 2017:13:1417-24.

11. Gorrod JW, Manson D. The metabolism of aromatic amines. Xenobiotica 1986; 16:933-55

12. Coleman S, Linderman R, Hodgson E, Rose RL. Comparative metabolism of chloroacetamide herbicides and selected metabolites in human and rat liver microsomes. Environ Health Perspect 2000;108:1151-7.

13. Brennan RJ, Schiestl RH. Aniline and its metabolites generate free radicals in yeast. Mutagenesis 1997;12:215-20.

14. Saad EA, Hassanien MM, El-Hagrasy MA, Radwan KH. Antidiabetic hypolipidemic and antioxidant activities andprotective effects of Punica granatum peels powder against pancreatic and hepatic tissues injuries in streptozotocin induced IDDM in rats. Int J Pharm Pharm Sci 2015;7:397-402

15. Saad EA, Toson EA, Ahmed GM. Clove green tea administration antagonizes khat hepatotoxicity in rats. Int J Pharm Pharm Sci 2015;7:72-6

16. Chao MW, Erkekoglu P, Tseng CY, Ye W, Trudel LJ, Skipper PL, et al. Intracellular generation of ROS by 3,5-dimethylaminophenol: Persistence, cellular response, and impact of molecular toxicity. Toxicol Sci 2014;141:300-13. 